J. Roger Maltby MB FRCA FRCPC

Michel T. Beriault MD FRCPC

Calgary, Alberta

\title{
REFERENCES
}

1 Oyston J. Abdominal distension during transurethral resection of a bladder tumour (Letter). Can J Anaesth 1998; 86: 1134.

2 Williams RT, Maltby JR. Airway intubator (Letter). Anesth Analg 1982; 61: 309.

3 Brimacombe JR, Barry AM, Campbell RC, Verghese $C$. Selection of the proper size of laryngeal mask airway in adults (Letter). Anesth Analg 1996; 83: 663-4.

4 Vyagis GS, Batzioulis PG, Secha-Doussaitou PN.

Selection of the proper size of laryngeal mask airway in adults (Letter). Anesth Analg 1996; 83: 663-4.

\section{Essential oil to promote inhalational induction in children}

To the Editor:

None of the volatile anesthetic agents have pleasant odours. We evaluated the use of essential oil of sweet orange to obscure the odour of sevoflurane and make it pleasant to inhale. One hundred and twenty children ASA 1 or 2 of both sexes aged between five and $14 \mathrm{yr}$ undergoing dental extraction participated in a randomised double blind trial.

A standard technique consisting of sevoflurane in $50 \% \mathrm{O}_{2}$ and $\mathrm{N}_{2} \mathrm{O}$ was used. In 60 children, the breathing filter was impregnanted with four drops of essential oil. After two breaths of gas mixture with sevoflurane $1 \%$ the child was asked to rate the odour of anesthetic vapour as pleasant, acceptable, unpleasant and horrid. Sevoflurane concentration was then rapidly increased to $8 \%$. Before discharge the children were asked to grade the acceptability of induction and whether they would like a similar technique used again in future.

Smooth induction was achieved in $85 \%$ of children in the essential oil group and the grading of anesthetic vapour odour was more favourable in this group $(72 \% v s 23 \%, P<0.05)$ as was acceptability of induction $(P<0.05)$. Children in the essential oil group were more likely to prefer a similar anesthetic technique in future $(82 \% v s 55 \%, P<0.05)$.

We have also used essential oil with halothane induction with excellent results.

S. Mehta

D.N. Stone

H.E. Whitehead

Burnley, England 